\title{
A Research on the Development of Remanufacturing Industry in the 14th Five-Year Plan Period
}

\author{
$\mathrm{Xu} \mathrm{Ye}{ }^{1, *}$ \\ ${ }^{1}$ School of Management Studies, Shanghai University of Engineering Science, Shanghai 201620, China
}

\begin{abstract}
Efficient use of resources and promotion of circular development are important tasks for strategic development during the 14th Five-Year Plan period. China actively promotes the development of the remanufacturing industry, but there is still room for improvement in many aspects such as the industry's laws and regulations, technical systems, and consumer awareness. Improving the remanufacturing industry system will help us meet future challenges. Combined with theoretical research, this research constructs a remanufacturing industry model. It analyzes the feasible measures of each subject to promote the development of the industry from the perspective of the return on the profits of the original manufacturers, remanufacturers and the government participating in the remanufacturing market.
\end{abstract}

\section{Introduction}

While technological advancement has brought convenience to mankind, it has also increased threats to the natural environment. Taking electromechanical products as an example, Chinese electromechanical products are abundant and the structure of industry is complex, including machine tools, engineering, automotive, electrical and electrical, aviation, agricultural machinery, ships, rail transit. The development of these industries has undoubtedly provided support for the better life of the people and the prosperity of the country. However, mechanical and electrical product waste has caused a series of problems such as the greenhouse effect, industrial pollution, energy crisis, it has also caused direct or indirect harm to human health. Therefore, it is urgent to properly handle mechanical and electrical product waste[1].

According to the Fifth Plenary Session of the 19th CPC Central Committee, the 14th Five-Year Plan period must accelerate the implementation of efficient use strategies to promote the development of cyclic development, and take the development of circular economy as a strategic support for high-quality economic development. In the field of industrial manufacturing, compared with manufacturing new products, product remanufacturing can cut costs, reduce energy consumption, save materials, and produce almost no solid waste[2]. Therefore, product remanufacturing is adapted to the transformation of Chinese economy from a rapid development stage to a high-quality development stage. This will be one of the best ways to strengthen the construction of ecological civilization.

\section{China reproduction industry status}

\subsection{National policy}

China highly attaches great importance to the strategic development of circular economy, and has successively promulgated a number of laws and regulations to support re-manufacturing industrial economy[3]. The Fourteenth Five-Year Plan for National Economic and Social Development of the People's Republic of China and the Outline of Long-term Goals for 2035 emphasizes the development and expansion of strategic emerging industries, and accelerates the transformation of green development. The government has adopted many measures to encourage the development of remanufacturing industry: increasing the construction of the construction re-manufacturing industry demonstration base, raising the number of pilot enterprises, gradually expanding the re-manufacturing product. A series of laws and regulations show the determination of the Chinese government to develop the remanufacturing industry. However, due to the late start of the industry, the relevant laws and regulations and management systems are immature, especially the intellectual property relationship between the original manufacturer and the remanufacturer. There is still a lot of work to be done in these areas.

\subsection{Technology system}

With the development of Chinese remanufacturing industry, remanufacturing technology has gradually formed a distinctive system. The use of advanced remanufacturing technology can reduce the consumption of raw materials and the production of replacement parts, 
which can bring huge environmental benefits[4]. In the high-level electromechanical product industry, the original manufacturer has a deep understanding of the overall theory and physical structure of the product, and the remanufacturer often lags behind in the performance evaluation of old parts, decomposition and cleaning, replacement and repair, and functional inspection. The original manufacturer, technical exchanges and cooperation between the two parties need to be strengthened. If the remanufacturing technology surpasses the original manufacturing technology, and the latest scientific and technological achievements are added to the remanufacturing of waste products, the overall performance of the remanufactured product can be optimized and it will have a place in the market.

\subsection{Consumer cognition}

Consumers are the end users of remanufactured products. Consumers' awareness of remanufactured products will affect the transformation of the final economic effects of remanufactured products. As China supports the development of the remanufacturing industry and the expansion of the old-for-new business, consumers' awareness of remanufactured products has improved. However, since some of the materials in the remanufactured products are derived from waste products, their quality will cause most consumers to question. Many developed countries have adopted policies to require remanufacturing companies to ensure the quality of remanufacturing, and on the other hand, consumers are encouraged to use remanufactured products, which are environmentally friendly. Remanufacturers adopt lower prices or better services for remanufactured products to improve consumers' awareness of consumption of remanufactured products. However, Chinese relevant remanufacturing system management standards need to be further clarified to improve consumers' awareness of remanufactured products.

In summary, China actively promotes the development of re-manufacturing industries, but in the industry's legal norm, technical system, consumer cognition, there is still progressive space, and improve the re-manufacturing industry system structure will help us to meet future challenges.

\section{Re-manufacturing industry model}

\subsection{Model framework}

The re-manufacturing industry is a huge circular economy system[5]. The original manufacturer acquires raw materials from raw material suppliers, using professional technical processing and production, and retailers are responsible for selling new products to consumers. The product has reached the life at the end of life, and the manufacturer recycles the old products. The original manufacturer provides technical support and intellectual property for re-manufacture. Re-manufacturing products are sold by retailers to consumers, completing the remanufacturing and value of the product. The process manufactured by the product is shown in Figure 1.

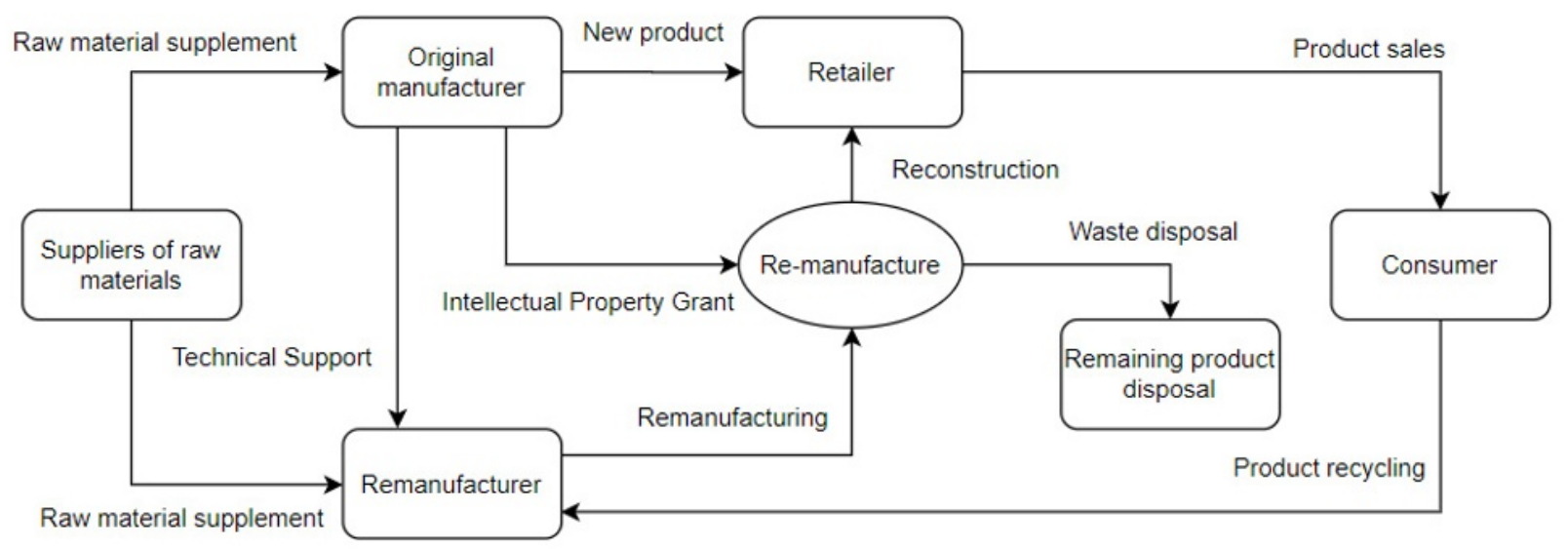

Figure 1 Remanufacturing industry model

Assumption 1. The economic participants in remanufacturing industry are rational economic mans, both the original manufacturer and the remanufacturer aim at profit maximization. The cost of the original manufacturer's new product is $C_{1}$ the market demand for new products is $D_{1}$, the sales income earns to $I_{1}$; the remanufacture of re-created products is $C_{2}$, the market demand for the re-creation is $D_{2}$ and the sales income earnings is $I_{2}$. Total customer product demand is $D$.

Assumption 2. Re-producer produces re-created raw materials from waste product recycling and supplementation of raw material suppliers, including the cost of purchasing supplemental raw materials has been included in the production of re-creation costs. Remanufacture recycling use of waste products is $R$, waste product recycling rate is $U$, product re-manufacturing intellectual property payment is $P$.

Assumption 3. Assuming that the ecological hazard of 3 re-product is much smaller than the ecological loss of new products, the government encourages the 
development of re-manufacturing industries and produces economic subsidies for re-manufacture production. The government's subsidy for re-posing is $S$, the ecological loss caused by new products is $H_{1}$, and the ecological loss of re-created production is $\mathrm{H}_{2}$.

\subsection{Analytical model}

Based on the above assumptions, the economic function of each participant in the remanufacturing industry can be obtained:

Original manufacturer's profit function,

$$
E_{1}=\left(I_{1}-C_{1}\right) \times D_{1}+P \times D_{2}
$$

Reproducer profit function,

$$
E_{2}=\left(I_{2}+S-C_{2}-P-R / U\right) \times D_{2}
$$

Government profit function,

$$
E_{3}=-\left[H_{1} \times D_{1}+\left(S+H_{2}\right) \times D_{2}\right]
$$

Connect formulas, it can present some main variables in the re-manufacturing industry model to the profit of market participants.

Considering that re-creates have special significance to environmental protection, the government tends to support the re-manufacture of re-manufacture through the form of re-manufacture of economic subsidies, so it is willing to pay for economic subsidies $\hat{S} \geq H_{1}-H_{2}$. The government gives subsidies after understanding the remanufacturing industry competitive market, which can improve the re-manufacture of profitability, the scale expansion of the incentive manufacturing industry, such initiatives can help environmental improvement[6]. The promulgation of specific regulations and policies should be combined with the market conditions of the remanufacturing target, coordinate the overall interests of the original manufacturer and the remanufacturer, and provide tax incentives for the original manufacturer that actively participates in the development of the remanufacturing industry, and awards for outstanding remanufacturers. Promote the development of the industry at an appropriate speed.

Original manufacturers sell intellectual property rights to re-manufacture, usually $\hat{P}<I_{1}-C_{1}$, in a good remanufacturing industry system, the benefits of original manufacturers generally lose due to consumers. However, the manufacturer should have sufficient social responsibility, on the basis of guaranteeing the good operation of the company, to bear some social responsibility is the obligation of sustainable development[7]. The original manufacturer can choose to withstand short-term economic losses and transfer part of the profits to customers to gain reputation, customer satisfaction and trust. Under the current productivity background, the original manufacturer is also a core role in the remanufacturing system, and the economic behavior of supporting remanufacturing is conducive to the longterm development of the enterprise.

Re-manufacture uses the original manufacturer to provide technical and intellectual property support for the remanufacturing of waste products, when $I_{2}+S-C_{2}-$ $P-R / U>0$, re-manufacture is interested in remanufacturing due to the driving drive. The recycling rate of re-manufacturers on waste products is an important factor in improving their profitability, which requires remanufacturers to familiarize with the physical structure and cleaning recovery steps of the waste products. The manufacturer should actively cooperate with the manufacturer to improve the re-manufacturing technology, to improve the closeness of the cooperation between the intellectual property rights, with a good renovated quality, the recognition of consumers is the heavy development of the re-manufacturing industry. In addition to cooperation between enterprises, strengthening industry-universityresearch cooperation is also effective for the research and development of core remanufacturing technologies and key facilities. Universities and scientific research institutes play an important role in the innovation and development. Enterprises can cooperate with universities and scientific research institutes to promote technological progress in manufacturing. Of course, it is important for consumers to increase their awareness of remanufactured products. This requires active publicity by companies or governments that expect the remanufacturing industry to flourish.

\section{Conclusion}

During the 14th Five-Year Plan period, the Chinese economy realized high-quality development, and the limited resources of high-efficiency utilization were an important part of highly quality development. Remanufacturing of high-value products is a cutting-edge technology with potential, which broadens the new direction of manufacturing. The development and progress of the industry cannot be completed overnight, but it requires sustained efforts. The development advancement of the re-manufacturing industry requires various participation subjects in the market. The government could encourage industry development, improves industry laws and regulations, coordinates the market partnership between manufacturers and remanufacturers, provides appropriate protection to remanufacturers, and provides economic subsidies to promote cooperation between the two parties; original manufacturers and remanufacturers work together to enhance re-manufacturing technology, actively adjust the price of remanufactured products, and give benefits to consumers; consumers increase use Consciousness of remanufactured products. The remanufacturing industry should fully integrate the market operation mechanism and actively use existing innovative technologies to achieve more breakthroughs under the promotion of the government.

\section{References}

1. Wenjun Zhou, Shumei Chen. The Status of Industrialization of Remanufacturing in China on the Basis of Ecological and Opening Economy[J]. 
Science and Technology Management Research, 2016,36(7):140-145+149.

2. Heng Jong Ngu, Man Djun Lee, Mohd Shahril Bin Osman. Review on current challenges and future opportunities in Malaysia sustainable manufacturing: Remanufacturing industries[J]. Journal of Cleaner Production,2020,273:123071.

3. Xin Yao. The Development of China Remanufacturing Industry Under Economic New Normal[J]. Scientific Management Research, 2017, 35(02):50-5.

4. Han-dong Zheng, En-zhong Li, Yan Wang, Pei-jing Shi, Bin-shi Xu, Shan-lin Yang. Environmental life cycle assessment of remanufactured engines with advanced restoring technologies[J]. Robotics and Computer-Integrated Manufacturing, 2019, 59:213-
221.

5. Guangdong Tian, Jiangwei Chu, Hesuan $\mathrm{Hu}$, Hongliang Li. Technology innovation system and its integrated structure for automotive components remanufacturing industry development in China[J]. Journal of Cleaner Production,2014,85:419-432.

6. Haike Qiao, Qin su. Impact of government subsidy on the remanufacturing industry[J]. Waste Management, 2021,120:433-447.

7. Tahir Islam, Rauf Islam, Abdul Hameed Pitafi, Liang Xiaobei, Mahmood Rehmani, Muhammad Irfan, Muhammad Shujaat Mubarak. The impact of corporate social responsibility on customer loyalty: The mediating role of corporate reputation, customer satisfaction, and trust $[\mathrm{J}]$. Sustainable Production and Consumption,2021,25:123-135. 